\title{
G to A Transition at Nucleotide 1,138 of the Complementary Deoxyribonucleic Acid of Fibroblast Growth Factor Receptor 3 Gene in a Japanese Girl with Achondroplasia
}

Noriyuki Katsumata, Toru Yasunaga, Toshiaki Tanaka, Ayako Tanae and Itsuro Hibi

Department of Endocrinology and Metabolism, National Children's Medical Research Center (NK, TY, TT), Division of Endocrinology and Metabolism, National Children's Hospital (AT, IH), Tokyo, Japan

Abstract It has recently been reported that point mutations in the fibroblast growth factor receptor 3 (FGFR3) gene, resulting in the substitution of an arginine residue for glycine at position 380 of the mature protein, cause of achondroplasia (ACH). In the present study we analyzed the FGFR3 gene of a 6 year old Japanese girl with ACH. Genomic deoxyribonucleic acid (DNA) of the patient was isolated from whole blood. A 164-bp fragment that spans the entire transmembrane domain was amplified by the polymerase chain reaction (PCR). A heterozygous $\mathrm{G}$ to A transition at nucleotide 1,138 of the complementary DNA (cDNA) was demonstrated by direct sequencing of the amplified DNA fragment, and this was confirmed by $S f c I$ digestion of the 164-bp PCR product. The 1,138A mutation results in the substitution of Arg for Gly at position 380 of the mature FGFR3 protein. The full role of the mutation remains to be determined.

Key words: achondroplasia, fibroblast growth factor receptor 3, point mutation

\section{Introduction}

$\mathrm{ACH}$, the most common genetic form of dwarfism, is inherited as an autosomal dominant trait with virtually complete penetrance, although the majority of the cases are sporadic. A gene for ACH was localized to 4p16.3 by linkage analysis (1-3). Furthermore, it has recently been reported that point mutations in the FGFR3 gene, which result in the substitution of an arginine residue for glycine at position 380 of the mature protein, cause ACH (4). In

Correspondence: Dr. Noriyuki Katsumata, Department of Endocrinology and Metabolism, National Children's Medical Research Center, 3-35-31, Taishido, Setagaya-ku, Tokyo 154 Japan the present study we analyzed the FGFR3 gene in a Japanese girl with ACH.

\section{Case Report}

The patient was born after an uneventful pregnancy and delivery. Her parents were healthy. Her birth weight was $2.9 \mathrm{~kg}$. She was diagnosed as suffering from $\mathrm{ACH}$ at 4 months of age from the typical physical features of this condition. Her intelligence was normal although motor development was slightly delayed. At 6 years of age she was admitted for endocrinological evaluation. Her height was $97.8 \mathrm{~cm}(-4.1 \mathrm{SD})$ and weight $19.2 \mathrm{~kg}(-0.8$ 


\section{Katsumata et al.}

SD). She had rhizomelic (short limbed) dwarfism, relative macrocephaly, a characteristic face with frontal bossing and midface hypoplasia and an exaggerated lumbar lordosis. Endocrinological examinations revealed normal hypophysial and thyroid functions.

There was no family history of ACH.

\section{Materials and Methods}

Genomic DNAs of the patient and from a normal subject were isolated from whole blood by proteinase $\mathrm{K}$ digestion and phenol/chloroform extraction. A 164-bp fragment of the FGFR3 gene that spans the entire transmembrane domain was amplified by the PCR as reported by Shiang $e t a l$, and the sequences of the primers were 5'AGGAGCTGGTGGAGGCTGA-3' and 5'-GGAGATCTTGTGCACGGTGG-3' (4). The nucleotide sequences were determined by direct sequencing of the asymmetric PCR products. The amplified PCR products were also analyzed by $S f c I$ digestion followed by agarose gel electrophoresis.

\section{Results and Discussion}

The DNA fragments of 164 bp were successfully amplified in the patient as well as in the normal subject.

A heterozygous $G$ to A transition at nucleotide 1,138 of the FGFR3 cDNA was demonstrated in the patient, while no mutation was detected in the normal subject (Fig. 1).

Since the G to A transition at nucleotide 1,138 in the sequence of the mutant allele creates a new restriction site for $S f c I$, restriction digestion of the PCR product from the mutant allele with $S f c I$ produces two fragments of 55 bp and 109 bp (Fig. 2). As shown in Fig. 3, only the 164-bp product was observed in the normal subject, and three fragments of $55 \mathrm{bp}, 109 \mathrm{bp}$, and $164 \mathrm{bp}$, respectively, were observed in the patient after $S f c I$ digestion, showing that the patient is a heterozygote for the mutation.

The 1,138A mutation results in the substitution of Arg for Gly at position 380 of the mature FGFR3 protein (Fig. 1). The missense point mutation G380R seems to have caused

\section{NORMAL PATIENT}
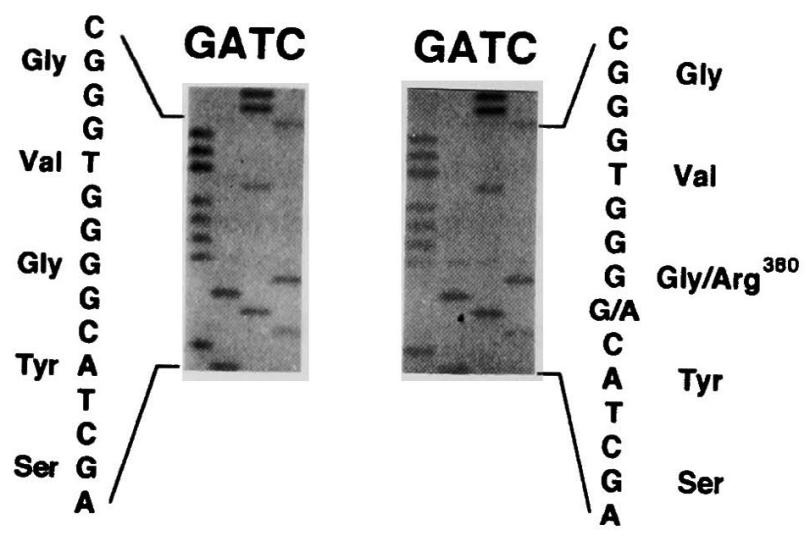

Fig. 1 Partial nucleotide sequence of the FGFR3 gene. Sequences were determined by direct sequencing of asymmetric PCR products. Note the heterozygous $\mathrm{G}$ to $\mathrm{A}$ transition at nucleotide 1,138 of the FGFR3 cDNA resulting in the substitution of Arg for Gly at position 380 of the mature protein in the patient.

\section{AGC TAC GGG GTG normal allele}

\section{AGC TAC $\triangle G G$ GTG G to A transition Sfcl}

Fig. 2 Sequence surrounding nucleotide 1,138. The $\mathrm{G}$ to $\mathrm{A}$ transition at 1,138 in the sequence of the mutant allele produces a new $S f c I$ restriction site. 


\section{A FGFR3 Mutation in Achondroplasia}

$\mathrm{ACH}$ in our patient. However, the full role of the G380R substitution in the pathogenesis of ACH remains to be determined.

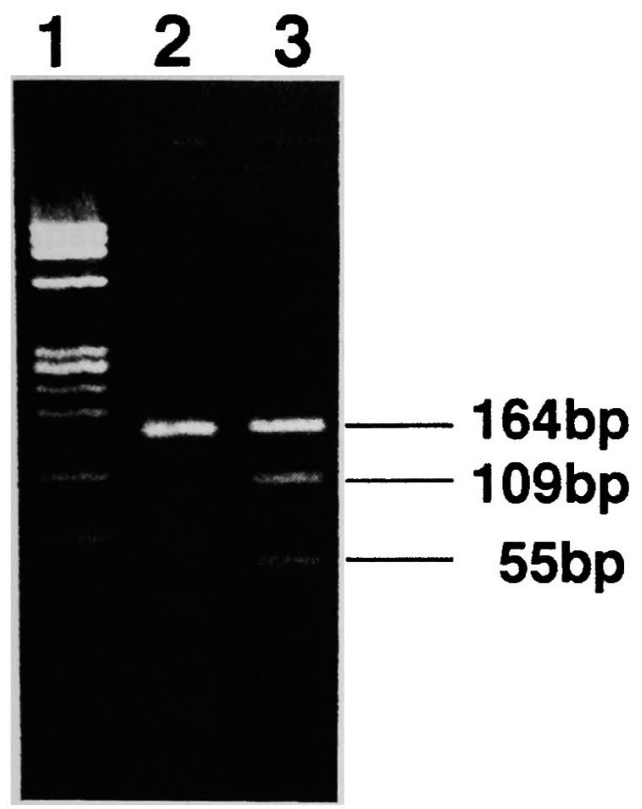

Fig. $3 \mathrm{SfcI}$ restriction analysis of 164-bp fragment of the FGFR3 gene. The PCR products of $164 \mathrm{bp}$ were digested with $S f c I$ and electrophoresis performed on a $3 \%$ NuSieve ${ }^{\circledR}$ GTG agarose gel: lane 1, HaeIII digested $\emptyset \mathrm{X} 174 \mathrm{RF}$ DNA; lane 2, PCR product from the normal subject; lane 3, PCR product from the patient with ACH. Only the 164-bp band is detected in the normal (lane 2), and three bands at sizes 163 bp, $109 \mathrm{bp}$, and $55 \mathrm{bp}$ are detected in the patient (lane 3).

\section{Acknowledgements}

We are grateful to Miss Atsuko Nagashima and Miss Kayo Nitta for technical assistance.

\section{References}

1. Velinov M, Slaugenhaupt SA, Stoilov I, Scott CI Jr, Gusella JF, Tsipouras P. The gene for achondroplasia maps to the telomeric region of chromosome $4 \mathrm{p}$. Nat Genet 1994; 6: 314-7.

2. Le Merrer M, Rousseau F, Legeai-Mallet L, Landais J-C, Pelet A, Bonaventure J, et al. A gene for achondroplasia maps to chromosome 4p. Nat Genet 1994; 6: 318-21.

3. Francomano CA, Ortiz de Luna RI, Hefferon TW, Bellus GA, Turner CE, Taylor $\mathrm{E}$, et al. Localization of the achondroplasia gene to the distal $2.5 \mathrm{Mb}$ of human chromosome 4p. Hum Mol Genet 1994; 3: 787-92.

4. Shiang R, Thompson LM, Zhu Y-Z, Church $\mathrm{DM}$, Fielder TJ, Bocian M, et al. Mutations in the transmembrane domain of FGFR3 cause the most common genetic form of dwarfism, achondroplasia. Cell 1994; 78: 335-42. 